\title{
Study on Electronic Energy Meter Failure Power Calculation Based on Metering Automation Systems
}

\author{
Gu Li ${ }^{1}$, Zhitian Jiang ${ }^{1}$, Xiaoyan $\mathrm{Yu}^{1}$, Zhirong $\mathrm{Cen}^{1}$, Jiefeng $\mathrm{Yan}^{1}$ \\ ${ }^{1}$ Foshan Power Supply Bureau, Guangdong Power Grid Co., Ltd., Foshan, Guangdong, 528000
}

\begin{abstract}
Whether the energy metering device is accurate or not is related to the economic interests of both the division and sale of electric power, but in reality, energy metering device failure is inevitable. When a failure occurs, it must be certain of the correct way to calculate the accrued power. Classic methods of electricity are estimated by returning and adding "correction coefficient", but the fault characteristics of electronic table differs from previous induction meter. Electrical parameters and the cumulative power is erratic, leading to "correction coefficient method" failure. This paper describes a means of electrical parameter automation metering systems continuously recorded using the thought of "integration", the correction coefficient to compensate for the lack of power to solve real projections fault electronic energy meter problem.
\end{abstract}

\section{Introduction}

In recent years, with good technical advantages in terms of energy metering, automated metering system has been promoted and applicated in Power Supply Bureau. Automation metering systems through the acquisition of the entire network voltage level of the electricity meter field measurement data and instantaneous data, including a diagram of the power, power sharing, freezing power, demand, voltage, current, etc., through statistics and analysis of the various data, automated meter reading management, line loss management, demand-side management and other applications. As a subsystem of automated metering system of the substation measurement, plant metering station automation system automating the collection, processing, storage providing data for line loss statistics and analysis for assessment, and passing electrical energy information, it can carry on real-time monitoring of the entire network effect measuring device.

Metering automation system is with historical data records and query functions. A detailed record of the measurement event of a fault meter for measurement management can query the point of failure, the observed fault changes and cause analysis was provided. The use of automated metering system, combined with thought of "integration" of the metering device during the power failure, has a greater advantage than conventional projection correction coefficient method. Through a typical case study, this paper introduces an application process integration method [1].

\section{The Fault Conditions}

On July 22, 2014, a team of metering grid operation and maintenance personnel from Power Supply Bureau monitored a $10 \mathrm{kV}$ substation meter line code table with stop progressive phenomenon through automation metering system.

Through the on-site inspection, the metered operation and maintenance personnel found that the normal line users of electricity metering secondary circuit wiring is correct, and the meter record current, voltage, active power, power factor and other data is normal, but stop progressive electricity meter (there are very few point in time with a small amount of progress). It determined that the meter internal components (suspected a counter) power meter power failure was caused by progressive stop. At 16:00 on July 22, they conducted a meter replacement process metering device back to normal.

Metering automation systems based on the recorded data determine the start time of time: June 15, 2014; the recovery time is at $16: 00$ on July 22, 2014; the cumulative failure time is $897 \mathrm{~h}$, see Table 1 .

\section{Remote Fault Diagnosis Technology}

The development of equipment condition monitoring and fault diagnosis has gone through a gradual process from stand-alone monitoring to distributed monitoring and diagnosis to remote monitoring and diagnosis. The remote fault diagnosis system is a network-based set of data acquisition, signal analysis, and status. The network 
integrated system integrating monitoring, expert diagnosis and fault prediction is a comprehensive application system integrating modern communication technology, computer technology, database technology and fault diagnosis technology. The biggest feature of remote fault diagnosis is the geographical separation of equipment and diagnostic resources. With the support of the network, the fault diagnosis and processing of remote faults is realized, which reduces maintenance costs and improves the timeliness and accuracy of diagnosis.

The methods of fault monitoring and diagnosis can generally be divided into three categories: pattern recognition [2].

Commonly used pattern recognition methods include statistical methods and fuzzy pattern recognition methods. The statistical method is characterized by calculating the statistical characteristics directly from the signal and selecting some components of the statistical features as fault features. The fuzzy pattern recognition method is longer than the empirical knowledge described by language, but usually does not have the ability to learn. It can only objectively select the membership function and fuzzy rules, and the diagnosis depends on the prior knowledge of the fault, so it can only find some common malfunction.

Rule-based reasoning, also known as artificial neural networks, stems from the ability of human brains to think, remember, and solve problems, inspiring many researchers to develop artificial neural networks. Its basic learning process is the same as that of biological nerves. It is characterized by self-learning through certain rules and strong anti-interference ability. When the fault condition is fully simulated and learned, the fault can be found almost $100 \%$. The disadvantage is that the internal expression of the network is difficult to know, and the actual fault does not occur frequently, so it is difficult to properly simulate and cannot obtain sufficient training data.

As a powerful tool for scientific research, mathematical models have long been used in machine fault diagnosis, especially in dynamic system fault diagnosis. This technology is very important. The disadvantage is that when the industrial process is complicated, it is generally difficult to obtain an accurate mathematical model. Usually, the approximate mathematical model can be obtained by the identification method, and sometimes the error of the approximate mathematical model is relatively large.

A single fault diagnosis method has its own advantages and disadvantages. Therefore, the crossintegration application of various methods to achieve complementary advantages is a trend. For example, the fuzzy neural network complements the fuzzy rules and the artificial neural network. On the one hand, the network can be constructed with the rules of language description, which makes the weight of the network have obvious meaning. On the other hand, the learning mechanism is introduced to improve the accuracy of knowledge representation. .

\section{Metering Automation System}

The metrology automation system consists of three parts: the smart meter and the terminal, the communication network such as carrier and wireless, and the measurement automation main station system. The smart meter and terminal are the sensing nodes of the intelligent metering automation system, just like the nerve endings of human beings, which is one of the important components of the intelligent energy metering system. Accurate and reliable operation of smart meters and terminals optimizes power production, transmission and use, and enables intelligent communication from power transmission and distribution to all aspects of the user. The main station of the metrology automation system is like the nerve center of the entire metrology automation system. It is mainly responsible for the data acquisition and monitoring functions of the metrology automation system. Through data aggregation and business processing to achieve power consumption monitoring, load control, line loss analysis, power quality analysis, customer energy assessment and other functions in large areas, provide a basis for power dispatching and power facility deployment in large areas.

In the development process of metering automation system based on remote meter reading, the earliest appeared is the energy metering telemetry system of the station. The International Electrotechnical Commission has established the IEC60870-5-102 (referred to as IEC102 standard) for the cumulative power transmission. It is the most widely used in system construction. With the development of social economy and the reform of the power system, the data information that needs to be collected needs to be more abundant. The content defined by the original IEC102 standard can no longer meet the needs of the current telecom measurement system construction of power companies. Guangdong Power Grid Corporation expanded the IEC102 standard content in 2006, and comprehensively promoted the construction of regional power grid telemetry systems in the province, and realized the full coverage of the plant station telemetry system. In 2005, Guangdong Power Grid Corporation took the lead in the large-scale introduction of large customer load management system construction, and integrated the power meter telemetry system of the station station on the basis of the main customer load management main station system, and connected the distribution monitoring and measurement system and low voltage. The user centralized meter reading system first proposed the concept of "electric energy metering automation system" and established an integrated metering automation system. At present, the focus of domestic research and development is on the construction of various types of metrology automation systems. The research on how to solve the problems of installation, commissioning and maintenance of on-site metrology automation terminals and on-site terminal fault diagnosis methods and means has not been involved [3].

\section{Fault Features Detection}

Metering secondary circuit wiring is correct, within meter record current, voltage, active power, power factor and 
other data is normal, but stop progressive electricity meter, the presence of a small amount of a very small part time schedule, the total failure of electricity close to zero.

The user load electricity law is significant. It rates during the valley time from 23:00 to 8:00 and suspends in the rest of the time. During operating period, the load is generally stable, and the load is also generally stable in suspension period, see Table 2.

Table 2. Active power instantaneous value

\begin{tabular}{|c|c|c|c|c|c|}
\hline \multicolumn{6}{|c|}{ Active power instantaneous value (excerpt) } \\
\hline \multirow{2}{*}{$\begin{array}{l}\mathrm{N} \\
\mathrm{o}\end{array}$} & \multirow{2}{*}{ Time } & \multicolumn{4}{|c|}{ Power(W) } \\
\hline & & Total & A & $\mathrm{B}$ & $\mathrm{C}$ \\
\hline 1 & $\begin{array}{l}2014-06- \\
1506: 00\end{array}$ & 79.30 & 31.00 & 0.00 & 48.30 \\
\hline 2 & $\begin{array}{l}2014-06- \\
1507: 00\end{array}$ & 79.20 & 30.90 & 0.00 & 48.30 \\
\hline 3 & $\begin{array}{l}2014-06- \\
1508: 00\end{array}$ & 78.40 & 31.10 & 0.00 & 47.20 \\
\hline 4 & $\begin{array}{l}2014-06- \\
15 \text { 09:00 }\end{array}$ & 3.60 & 1.60 & 0.00 & 1.90 \\
\hline 5 & $\begin{array}{l}2014-06- \\
1510: 00\end{array}$ & 3.20 & 1.40 & 0.00 & 1.80 \\
\hline 6 & $\begin{array}{l}2014-06- \\
1511: 00\end{array}$ & 3.20 & 1.60 & 0.00 & 1.50 \\
\hline 7 & $\begin{array}{l}2014-06- \\
1512: 00\end{array}$ & 2.80 & 1.30 & 0.00 & 1.50 \\
\hline 8 & $\begin{array}{l}2014-06- \\
1513: 00\end{array}$ & 6.70 & 2.70 & 0.00 & 3.90 \\
\hline 9 & $\begin{array}{l}2014-06- \\
1514: 00\end{array}$ & 7.90 & 3.20 & 0.00 & 4.60 \\
\hline 10 & $\begin{array}{l}2014-06- \\
1515: 00\end{array}$ & 5.70 & 2.50 & 0.00 & 3.10 \\
\hline 11 & $\begin{array}{l}2014-06- \\
1516: 00\end{array}$ & 7.40 & 2.50 & 0.00 & 4.80 \\
\hline 12 & $\begin{array}{l}2014-06- \\
1517: 00\end{array}$ & 5.60 & 2.00 & 0.00 & 3.60 \\
\hline 13 & $\begin{array}{l}2014-06- \\
1518: 00\end{array}$ & 2.00 & 1.00 & 0.00 & 1.00 \\
\hline 14 & $\begin{array}{l}2014-06- \\
1519: 00\end{array}$ & 0.60 & 0.10 & 0.00 & 0.40 \\
\hline 15 & $\begin{array}{l}2014-06- \\
1520: 00\end{array}$ & 0.80 & 0.30 & 0.00 & 0.50 \\
\hline 16 & $\begin{array}{l}2014-06- \\
1521: 00\end{array}$ & 1.20 & 0.70 & 0.00 & 0.50 \\
\hline 17 & $\begin{array}{l}2014-06- \\
1522: 00\end{array}$ & 1.40 & 0.70 & 0.00 & 0.60 \\
\hline 18 & $\begin{array}{l}\text { 2014-06- } \\
1523: 00\end{array}$ & 41.50 & 16.90 & 0.00 & 24.50 \\
\hline 19 & $\begin{array}{l}2014-06- \\
1600: 00\end{array}$ & 80.70 & 31.80 & 0.00 & 48.80 \\
\hline 20 & $\begin{array}{l}2014-06- \\
1601: 00\end{array}$ & 78.90 & 31.10 & 0.00 & 47.80 \\
\hline 21 & $\begin{array}{l}2014-06- \\
1602: 00\end{array}$ & 78.60 & 30.70 & 0.00 & 47.90 \\
\hline
\end{tabular}

\section{Traditional Methods and Their Limitations}

When the power measurement device fault (wiring error), according to the general expression of the power ratio respectively, and calculate the correction coefficients at the correct time and trouble. Correction coefficient is the ratio of the value of electric power in the secondary circuit failure under certain circumstances, the electric

power meter value should be measured $\mathrm{p}$ meter malfunction meter metered, namely:

$K=\frac{\mathrm{P}}{\mathrm{p}^{\prime}}$

Then, the correction coefficient $\mathrm{K}$ multiplied by the measured fault meter electric energy $\mathrm{W}$ is the actual power value $\mathrm{W}$ [4].

In the conventional methods, we need to know the power failure $\mathrm{W}^{\prime}$, then the expression of power failure $\left(\mathrm{P}^{ }\right)$based on an error in the form of secondary circuit wiring lists, and then calculate the correction coefficient $\mathrm{K}$, to finally determine the "correct charge W". However, in this fault, the secondary circuit wiring error does not exist, and it cannot come to "correction coefficient $\mathrm{K}$ ". More particularly, this fault is "stop code table progressive," which cause cannot be determined by "power failure expression $\left(\mathrm{P}^{\prime}\right)$ ". Thus, the conventional correction factor method cannot solve this failure, see Table 3 .

\section{Function of Automation Metering System}

Metering automation systems record historical data and query capabilities, while continuous process meter timer records operation of the voltage, current, instantaneous power, energy and other information.

It should be noted that, factory automation systems read metering station peak power, voltage, current, active data such as reading a multi-function table of the whole point in the division within an hour (00 points), so "meritorious here power "physical meaning is indeed" the whole point of the instantaneous power. "

\section{Application of Integration Method}

This paper uses "integration method" to solve this problem. According to observation of the load current trends, it can be found that if there is unit of 1 hour, the load variation of the user is relatively stable. Thus it can be assumed: generally stable in every hour $\Delta \mathrm{h}$ in the power $(\mathrm{P})$, with little change, so you can use automated metering system to record it, "the whole point of the instantaneous power $(\mathrm{P} 0)$ " to calculate the power $\Delta \mathrm{W} \Delta \mathrm{h}$ within the following the intervals were calculated narrowed to $\Delta \mathrm{h}$ (1 hour) [5].

You can excel editing formulas to automatically calculate the correct power $\Delta \mathrm{h}$ (1 hour) within the $\left(\Delta \mathrm{W}^{`}\right)$, error $\triangle \mathrm{W} 0$ electricity, etc., and use sum () function for automatically $\Sigma$ cumulation.

$\triangle \mathrm{h}$ within the correct power is: $\Delta \mathrm{W}^{\prime}=\mathrm{P} 0 \times \Delta \mathrm{t}$.

Error is within the power $\Delta \mathrm{h}: \Delta \mathrm{W} 0^{`}=\Delta \mathrm{W}^{`}-(\mathrm{W} 2-$ W1) 
Wherein, W1, W2 is the active power down time of the beginning and end table code.

Error power failure time is: $\Delta \mathrm{W}_{0}=\Sigma \Delta \mathrm{W}_{0}{ }^{\circ} \times$ total magnification

$\triangle \mathrm{W}_{0}=\Sigma \triangle \mathrm{W}_{0} \times$ total magnification $=22.28 \times 5000=$ $1114000 \mathrm{kWh}$

Namely: less computing power during a malfunction of the feeder meter substation $10 \mathrm{KV}$, it should be retroactive $1114000 \mathrm{kWh}$.

Downtime error within the power of computing in excel spreadsheet can edit formulas calculated.

\section{Conclusion}

The principle of integration is based on the correction coefficient, by dividing the time and assuming that accumulates at each calculated parameter values within the split ratio $\triangle \mathrm{h}$ time without changing to arrive at the correct error power. It makes up the shortcomings of traditional correction coefficient methods, and it can solve the fault current and voltage power return \& add erratic changes in the case of calculation, and makes return \& add power calculation to be more accurate. The integration method has wide range of application, especially as it has large advantage on dealing with changes in the value of the instantaneous case.

\section{References}

1. DL/T448-2000, People's Republic of China power industry standard means Technical Management Rules energy metering [S].

2. Li Gu. The method of voltage transformer secondary circuit voltage drop [J]. An indirect measure of Guangdong Electric Power .2014.12: 84-87.

3. Zhao Quanle. Line Loss Management Manual[M]. Beijing: China Electric Power Press, 2007

4. Jin Xizhu. Phase three-wire run combined transformer metering Common Fault Analysis [J]. Metering technology, 2012 (12).

5. Zheng Jian, the power meter and other dynamic characteristics of the experimental study [J]. Electrical Measurement \& Instrumentation, 2011, (3).

Table 1. Tables and related information at the end of the power failure

\begin{tabular}{|c|c|c|c|c|c|c|c|c|c|c|}
\hline \multirow{2}{*}{\multicolumn{2}{|c|}{ Table class }} & \multirow{3}{*}{$\begin{array}{l}\text { type } \\
\text { DSSD5 }\end{array}$} & \multirow{3}{*}{$\begin{array}{l}\text { Factory } \\
\text { Hualong }\end{array}$} & \multirow{3}{*}{$\begin{array}{l}\text { No. } \\
3030000429\end{array}$} & \multicolumn{4}{|c|}{ Hourly metering base } & \multirow{3}{*}{$\begin{array}{l}\text { Hourly } \\
50000\end{array}$} & \multirow{3}{*}{$\begin{array}{l}\text { CT } \\
500 / 1\end{array}$} \\
\hline & & & & & \multirow{2}{*}{$\begin{array}{l}\text { peak } \\
196.97\end{array}$} & \multirow{2}{*}{$\frac{\text { Valley }}{1053.08}$} & \multirow{2}{*}{\begin{tabular}{|l|} 
Normal \\
637.95
\end{tabular}} & \multirow{2}{*}{$\frac{\text { Total }}{1888.00}$} & & \\
\hline Before a & Power & & & & & & & & & \\
\hline occurs & None & DSSD5 & Hualong & 3030000429 & 67.35 & 401.28 & 232.32 & 700.95 & 50000 & $500 / 1$ \\
\hline \multirow{2}{*}{ End Fault } & Power & DSSD5 & Hualong & 3030000429 & 197.06 & 1055.79 & 638.41 & 1891.26 & 50000 & $500 / 1$ \\
\hline & None & DSSD5 & Hualong & 3030000429 & 67.44 & 409.72 & 233.39 & 710.55 & 50000 & $500 / 1$ \\
\hline
\end{tabular}

Table 3. Active power instantaneous value

\begin{tabular}{|c|c|c|c|c|c|c|c|}
\hline \multicolumn{6}{|c|}{ Active power instantaneous value (excerpt) } & \multirow{3}{*}{$\frac{\triangle \mathrm{W}}{\triangle \mathrm{h}}$} & \multirow{3}{*}{$\frac{\Delta \mathrm{W} 0}{\Delta \mathrm{h}}$} \\
\hline \multirow{2}{*}{ No. } & \multirow{2}{*}{ time } & \multicolumn{4}{|c|}{ Power(W) } & & \\
\hline & & Total & A & B & C & & \\
\hline 1 & $\begin{array}{l}2014-06-15 \\
06: 00\end{array}$ & 79.30 & 31.00 & 0.00 & 48.30 & 0.07930 & \\
\hline 2 & $\begin{array}{l}2014-06-15 \\
07: 00\end{array}$ & 79.20 & 30.90 & 0.00 & 48.30 & 0.07920 & \\
\hline 3 & $\begin{array}{l}2014-06-15 \\
08: 00\end{array}$ & 78.40 & 31.10 & 0.00 & 47.20 & 0.07840 & \\
\hline 4 & $\begin{array}{l}2014-06-15 \\
09: 00\end{array}$ & 3.60 & 1.60 & 0.00 & 1.90 & 0.00360 & \\
\hline 5 & $\begin{array}{l}2014-06-15 \\
10: 00\end{array}$ & 3.20 & 1.40 & 0.00 & 1.80 & 0.00320 & \\
\hline 6 & $\begin{array}{l}2014-06-15 \\
11: 00\end{array}$ & 3.20 & 1.60 & 0.00 & 1.50 & 0.00320 & \\
\hline$\ldots$ & $\ldots \ldots$ & $\ldots$ & $\ldots$ & & $\ldots$ & $\ldots$ & $\ldots$ \\
\hline$\sum$ & total & / & / & 1 & / & 25.54 & 22.28 \\
\hline
\end{tabular}

